ISSN: 2162-3104 Print/ ISSN: 2166-3750 Online

Volume 10, Issue S3 (2020), pp. 44-57

(C) Journal of International Students

https://ojed.org/jis

\title{
The Psychological Well-Being of Newly-Arrived Indonesian Students in Taiwan
}

\section{Kesejahteraan Psikologis Mahasiswa Baru Indonesia di Taiwan}

\author{
Ferry Fadzlul Rahman \\ Universitas Muhammadiyah Kalimantan Timur, Indonesia \\ Asia University, Taiwan \\ Hamka \\ Universitas Muhammadiyah Kalimantan Timur, Indonesia \\ Asia University, Taiwan
}

Kuan-Han Lin

Asia University, Taiwan

\begin{abstract}
A study abroad program is of great interest among high school leavers globally. Indonesian school leavers are no exception. This study investigates the psychological well-being of Indonesian students studying at Taiwanese universities. Informed by a phenomenological approach, sixteen Indonesian participants who studied in Taiwan were recruited for this case study. Data were garnered from semi-structured interviews and observations. The findings of the study show that the students were unable to manage their emotions (e.g., culture shock, a feeling of being isolated) and adapt with different culture and language.

ABSTRAK: Program belajar di luar negeri sangat menarik bagi lulusan sekolah menengah secara global, tidak terkecuali lulusan sekolah di Indonesia. Penelitian ini bertujuan untuk mengkaji kesejahteraan psikologis mahasiswa Indonesia di Taiwan. Penelitian ini menggunakan desain studi kasus fenomenologi. Partisipan penelitian ini adalah mahasiswa dari Indonesia yang belajar di Taiwan. Wawancara semi-terstruktur dan observasi digunakan untuk pengumpulan data. Hasil penelitian menunjukkan bahwa mahasiswa belum mampu mengelola emosi (misalnya, gegar budaya, perasaan terisolasi) dan beradaptasi dengan budaya dan bahasa yang berbeda dari negara asal.
\end{abstract}


Keywords: Case study, Indonesia, newly-arrived students, psychological well-being [Studi kasus, Indonesia, mahasiswa baru, kesejahteraan psikologis]

\section{PENDAHULUAN}

Dalam beberapa tahun terakhir, terjadi peningkatan kerja sama internasional dalam bidang pendidikan tinggi. Kerja sama ini berdampak pada perluasan skema pertukaran mahasiswa dan agenda kurikulum internasional serta peluang penerimaan mahasiswa internasional (Unanue, Vignoles, Dittmar \& Vansteenkiste, 2016). Tidak mengherankan jika terdapat banyak mahasiswa baru, termasuk dari Indonesia yang menempuh pendidikan tinggi di luar negeri. Alasan calon mahasiswa dari Indonesia untuk mencari universitas di luar negeri adalah untuk memiliki pengalaman pendidikan yang lebih baik daripada mencari pengalaman studi di dalam negeri. Salah satu negara yang memiliki universitas terbaik yang diminati oleh mahasiswa baru dari Indonesia adalah Taiwan. Data tahun 2018 yang dilangsir oleh Taipei Economic and Trade Office (TETO) menunjukkan sekitar 7.000 mahasiswa yang terdaftar di universitas Taiwan.

Mahasiswa baru dituntut untuk dapat menyesuaikan diri dengan lingkungan akademik yang baru untuk memudahkan mereka dalam proses pembelajaran dan mencapai tujuan belajar (Harvey, 2017). Banyak kendala yang dihadapi oleh mahasiswa, terutama mahasiswa baru internasional di perguruan tinggi. Misalnya, mahasiswa akan bertemu dengan budaya akademik dan non-akademik serta bahasa baru yang menuntut mereka untuk beradaptasi dengan lingkungan akademik dan masyarakat setempat. Seringkali, mahasiswa internasional harus bernegosiasi dengan dirinya sendiri dalam proses adaptasi budaya akademik dan bahasa. Proses negosiasi dan adaptasi ini tidak terlepas dari aspek psikologis, seperti kecemasan, ketidakpercayaan diri, gegar budaya dan aspek psikologis lainnya yang memengaruhi kualitas hidup mahasiswa internasional. Hal tersebut mungkin mengancam perasaan, identitas dan kesejahteraan psikologis mereka (Yilmaz, Sahin \& Nazli, 2020). Beberapa penelitian melaporkan bahwa mahasiswa yang menempuh pendidikan di luar negeri mengalami berbagai tantangan akademik dan sosial-budaya. Tantangan tersebut mencakup hambatan bahasa, perbedaan budaya, kerinduan akan kampung halaman (Cao, Zhu \& Meng, 2016), kurangnya dukungan sosial, kurangnya efikasi diri dan keadaan stres yang berlebihan (Zhang \& Goodson, 2011), akulturasi stres, penyesuaian psikologis, kepemilikan sosial, depresi dan kegelisahan (Brunsting, Zachry \& Takeuchi, 2018).

Penyesuaian diperlukan oleh setiap mahasiswa baru, termasuk mahasiswa baru dari Indonesia yang belajar di Taiwan. Leathwood dan O'Connell (2003) mengamati bahwa mahasiswa baru sering mengalami masalah yang berhubungan dengan kesejahteraan psikologis. Manusia yang memiliki kesejahteraan psikologis tidak hanya memiliki mental yang positif, tetapi juga dapat menerima diri sendiri, memiliki hubungan dengan orang lain dan memiliki kemampuan untuk memiliki sesuatu dan mengembangkan diri (Akhtar \& Kroener-Herwig, 2019). Selain masalah kesejahteraan psikologis, masalah 
lain yang terjadi, khususnya pada mahasiswa muslim adalah kesulitan menemukan tempat makan (restoran) yang menyajikan makanan halal serta tempat ibadah. Hal ini dapat memengaruhi kesejahteraan psikologis mahasiswa baru yang belajar di luar negeri (Chen, Liu, Tsai \& Chen, 2015). Untuk itu, mahasiswa baru harus memiliki strategi dalam menjalani kehidupan barunya, terutama dalam menyesuaikan diri dengan lingkungan (Chen, Liu, Tsai \& Chen, 2015). Mahasiswa yang mampu menyesuaikan diri dengan lingkungan sosial yang lebih tinggi dapat membangun kompetensi yang diperlukan dalam menciptakan lingkungan yang sesuai dengan kebutuhan (Chen, Liu, Tsai \& Chen, 2015).

Beberapa penelitian menggambarkan kehidupan akademik dan sosial di universitas luar negeri yang menantang bagi mahasiswa karena mereka harus beradaptasi dengan beragam hal, termasuk mampu mengelola stres saat memulai perkuliahan (Huffman, Inoue, Asahara, Oguro, Okubo, Umeda \& Shimoda, 2020; Yilmaz, Sahin, \& Nazli, 2020). Batram (2008) menyarankan perlunya dukungan bagi mahasiswa baru internasional berupa kebutuhan sosial budaya dan kebutuhan akademik. Hal ini mencakup informasi akomodasi, dukungan jejaring sosial, lingkungan belajar yang mendukung, bantuan program bahasa, yang dapat berimplikasi pada kesejahteraan psikologis mahasiswa. Untuk menambahkan riset-riset sebelumnya mengenai kajian psikologi sosial mahasiswa internasional, penelitian ini mengeksplorasi kondisi kesejahteraan psikologis mahasiswa baru dari Indonesia ketika belajar di Taiwan, khususnya dimensi pendidikan, budaya dan sosial.

\section{KAJIAN PUSTAKA}

\section{Kesejahteraan Psikologis Mahasiswa dari Perspektif Pendidikan}

Pada tingkat paling mendasar, kesejahteraan psikologis sangat mirip dengan kondisi mental positif seperti kebahagiaan atau kepuasan. Aspek kesejahteraan psikologis ini disebut sebagai kesejahteraan subjektif (eudaimonic) yang memiliki dua komponen, yaitu komponen afektif dan komponen kognitif yang berkaitan dengan kepuasan individu terhadap kehidupannya (Carruthers \& Hood, 2004). Kesejahteraan eudaimonic ini mengacu pada kemampuan individu untuk menggali potensi yang ada di dalam dirinya secara maksimal, sehingga menjadi individu yang bermanfaat bagi orang lain (Ryff, 1995).

Mahasiswa internasional adalah bagian utama dari program internasionalisasi pendidikan tinggi di lembaga-lembaga pendidikan di dunia. Program ini dapat digambarkan sebagai proses adaptasi antarbudaya dalam menyelenggarakan pendidikan yang meliputi pengajaran, pembelajaran, penelitian dan fungsi layanan terkait. Pendidikan di perguruan tinggi memberikan pengalaman positif dan menawarkan berbagai kesempatan bagi mahasiswa untuk beradaptasi dengan nilai-nilai lingkungan baru (Tanis, 2013). Namun demikian, dalam proses tersebut, para mahasiswa di luar negeri mengalami proses akulturasi (Rujipak \& Limprasert, 2016). Mahasiswa internasional kemungkinan akan mendapatkan tantangan serta tekanan adaptasi 
yang tinggi dalam orientasi budaya baru di negara tuan rumah pada periode awal (Akhtar \& Kroener-Herwig, 2019).

Untuk membantu mahasiswa dalam beradaptasi dalam proses akulturasi tersebut, Ryff dan Singer (1996) memaparkan faktor yang dapat menentukan kesejahteraan psikologis, yaitu (1) penerimaan diri, (2) hubungan baik dengan sesama, (3) pengendalian diri, (4) kemandirian, (5) penentuan tujuan hidup dan (6) perencanan pengembangan diri. Namun, keenam faktor tersebut tidak dapat dipahami sebagai satu kesatuan yang saling berkaitan sehingga diklasifikasikan menjadi tiga dimensi, yaitu dimensi budaya, pendidikan dan sosial. Paige dan Cohen (2012) mendefinisikan budaya sebagai pola perilaku dan interaksi, konstruksi kognitif dan pemahaman yang dipelajari melalui sosialisasi. Mahasiswa yang belajar di luar negeri sering mengalami masalah budaya karena kesulitan dalam menyesuaikan diri di lingkungan sosial sehingga mengalami gegar budaya (culture shock). Gegar budaya merupakan kondisi gelisah dan bingung yang dirasakan oleh seseorang ketika meninggalkan budaya yang telah familier dan tinggal di tempat yang memiliki budaya baru (Paige \& Cohen, 2012).

Dalam proses pendidikan internasional, mahasiswa internasional menghadapi berbagai masalah ketika mereka tinggal dan belajar di luar negeri. Poyrazli, Kavanaugh, Baker dan Al-Timimi (2004) mengungkapkan masalah tersebut umumnya terkait dengan kesulitan bahasa, adaptasi dengan sistem pembelajaran yang baru dan kondisi psikologis (seperti perasaan rindu, perlakuan yang berbeda dan terisolasi). Perasaan rindu adalah perasaan yang muncul bersamaan dengan rasa suka terhadap suatu objek yang membuat bahagia atau pengalaman menyenangkan (Moeller \& Seehuus, 2019). Perlakuan berbeda adalah perlakuan diskriminasi yang dilakukan orang lain terhadap individu sehingga mengakibatkan perasaan tidak nyaman (Yamada, Klugar, Ivanova \& Oborna, 2014). Isolasi adalah perasaan terasing yang dialami oleh individu dalam daerah atau situasi baru (Will, 2016). Masalah lain yang dihadapi oleh mahasiswa internasional adalah kendala sosial budaya, sistem kesehatan dan keuangan (Vande Berg, 2007).

Dimensi sosial lainnya berupa diskriminasi struktural terhadap kelompok tertentu yang tidak terwakili di pendidikan tinggi, didasarkan pada latar belakang sosial ekonomi dan latar belakang budaya atau etnis. Dalam dimensi sosial, penyediaan layanan konseling diperlukan mahasiswa selama proses penyelesaian studi di luar negeri (Niehaus, Bryan, Nelson \& Briscoe, 2020).

\section{METODE PENELITIAN}

\section{Konteks dan Partisipan}

Penelitian ini menggunakan metode penelitian studi kasus fenomenologi, yang memungkinkan peneliti untuk memahami esensi pengalaman manusia secara berurutan dari perspektif partisipan sebagai pemberi informasi pertama (Gallagher, 2012). Data dikumpulkan dari mahasiswa baru asal Indonesia di 
salah satu universitas di Taiwan. Pengumpulan data dilaksanakan mulai dari bulan November 2018 sampai dengan Januari 2019. Partisipan berjumlah 16 orang (lihat Tabel 1) yang direkrut berdasarkan tujuan penelitian yang melibatkan partisipan laki-laki dan perempuan dan berstatus sebagai mahasiswa penuh waktu.

Tabel 1. Identitas partisipan

\begin{tabular}{lll}
\hline Nama & Jenis Kelamin & Umur \\
(anonim) & & 19 \\
AG & Laki-laki & 20 \\
IB & Perempuan & 19 \\
YN & Perempuan & 19 \\
RB & Perempuan & 20 \\
YD & Laki-laki & 21 \\
HB & Laki-laki & 20 \\
AL & Perempuan & 21 \\
BC & Laki-laki & 22 \\
BI & Laki-laki & 20 \\
AN & Perempuan & 22 \\
DF & Laki-laki & 20 \\
FR & Laki-laki & 19 \\
HA & Laki-laki & 20 \\
IG & Laki-laki & 19 \\
MD & Perempuan & 19 \\
RS & Perempuan & \\
\hline
\end{tabular}

Partisipan merupakan mahasiswa baru dengan jenjang pendidikan strata satu (sarjana S-1) dengan jumlah total enam belas partisipan (16), sembilan berjenis kelamin laki-laki dan tujuh partisipan perempuan. Partisipan termuda berusia sembilan belas (19) tahun dan yang tertua berusia dua puluh dua tahun (22). Mereka memiliki latar belakang bahasa dan budaya yang berbeda, sehingga memberi nuansa pengalaman yang unik. Hal ini mengindikasikan bahwa pengalaman akademik dan non-akademik yang mereka alami di negara orang lain mungkin dipengaruhi oleh latar belakang tersebut.

\section{Prosedur Pengambilan Data}

Rekrutmen partisipan dimediasi oleh asosiasi mahasiswa Indonesia. Peneliti menghubungi ketua asosiasi mengenai panduan riset yang sesuai, seperti mengirim surat undangan wawancara kepada calon peserta. Calon partisipan penelitian direkrut berdasarkan kriteria yang ditetapkan, seperti mahasiswa baru berasal dari Indonesia yang sudah menetap di Taiwan selama tiga bulan. Setelah peneliti melakukan pengecekan kelayakan calon partisipan, mereka diberi surat persetujuan. Setelah itu, peneliti memberikan panduan wawancara dan menyepakati jadwal tatap muka untuk melakukan wawancara langsung. Pada akhir wawancara, para peserta diberi kesempatan untuk mengklarifikasi ulang informasi yang telah diberikan, termasuk kerahasiaan identitas mereka dalam laporan penelitian (Widodo, 2014). 
Instrumen yang digunakan untuk mengumpulkan data dikembangkan berdasarkan konstruk kesejahteraan psikologis yang diadaptasi dari Scale of Psychological Well-Being (Ryff, 1995). Dalam hal ini, mahasiswa diminta untuk memberikan informasi terkait kesulitan yang dialami dari segi sosial budaya dan proses belajar, serta pengalaman baru yang tidak dialami di Indonesia. Selain itu, partisipan ditanya mengenai tuntutan kehidupan seharihari dan bentuk dukungan sosial dari teman, kampus dan organisasi. Pendekatan observasi partisipan dilakukan untuk mengamati kegiatan keseharian partisipan. Perekaman data observasi ini berbentuk catatan lapangan kecil guna memaparkan hasil observasi secara sistematik.

\section{Analisis Data}

Setelah mendapatkan data wawancara dan observasi, peneliti melakukan transkripsi data wawancara yang dilanjutkan dengan menganalisis data. Analisis yang digunakan adalah grounded theory yang memungkinkan peneliti untuk mengkaji uraian terperinci tentang sifat/karakteristik data yang dikumpulkan, sebelum mencoba menghasilkan pernyataan teoretis yang lebih umum. Ketika catatan cadangan yang memadai memiliki deskripsi akurat tentang fenomena sosial yang relevan, peneliti mulai membuat premis keterkaitan antara fenomena yang ada kemudian mengaitkan dengan bagian data lainnya. Grounded theory adalah metodologi riset kualitatif yang menjelaskan petunjuk secara sistematis untuk pengumpulan dan analisis data dengan tujuan membangun kerangka teori (Reiter, Stewart \& Bruce, 2011). Semua data kemudian dikodekan ulang sesuai dengan kerangka teori. Untuk memastikan kredibilitas dan keterpercayaan prosedur analisis data, kutipan yang relevan dari masing-masing tema dimunculkan untuk menggambarkan dan mendukung temuan. Identifikasi hasil memungkinkan untuk menggali pandangan serta pengalaman para partisipan yang dianalisis dalam dimensi sosial, pendidikan dan budaya.

\section{TEMUAN DAN PEMBAHASAN PENELITIAN}

Mahasiswa baru dari Indonesia menyatakan bahwa ketika belajar di Taiwan terdapat banyak hal yang diperoleh termasuk wawasan tentang konsep budaya, pendidikan dan sosial. Mahasiswa baru dari Indonesia dan dari beberapa negara lain diharuskan untuk belajar bahasa Mandarin dan bahasa Inggris, sehingga dapat membantu berkomunikasi dengan mahasiswa dari negara lain dan penduduk setempat.

Pertanyaan yang diberikan kepada partisipan tidak secara khusus membahas kesejahteraan psikologis misalnya: menurut Anda kesulitan apa yang dihadapi sebagai mahasiswa baru di luar negeri? Beberapa partisipan menanggapi kesejahteraan psikologis yang mereka alami, seperti upaya untuk beradaptasi dengan kebudayaan baru terutama mengenai makanan dan bahasa. Dalam dimensi pendidikan, mahasiswa tertantang untuk mengedepankan sifat disiplin dan profesional dalam bidang akademik maupun non-akademik. Dari 
dimensi sosial, mahasiswa mengalami krisis kepercayaan diri di awal perkuliahan dalam hal berkomunikasi dengan penduduk asli Taiwan yang mengakibatkan gegar budaya. Dari dimensi budaya, mahasiswa perlu beradaptasi dengan norma dan kebiasaan masyarakat setempat yang menerapkan perilaku jujur dan tertib.

\section{Dimensi Pendidikan: "Kami tertantang untuk menjadi lebih profesional dan disiplin"}

Negara Taiwan menerapkan sistem pendidikan yang mengedepankan kedisiplinan dan profesionalitas. Misalnya, dosen selalu datang dan pulang tepat waktu dan memperhatikan kebutuhan mahasiswanya. Sebagian besar mahasiswa baru juga mendapatkan pengalaman baru, terutama tentang konsep belajar dari universitas yang mereka inginkan, dan belajar tentang karakter orang di negara lain. Salah satu partisipan berkomentar:

Sangat berbeda bagi saya karena dari latar belakang saya berasal, sebagian besar dari apa yang Anda pelajari di kelas dan ketika saya datang ke sini dan harus membaca jurnal dan membaca banyak literatur dan dosen selalu datang on time dan menanyakan apa yang diperlukan mahasiswa internasional dalam membahas materi, itu tidak seperti sebelumnya jadi saya harus terbiasa dengan itu. (Yd. November 2018)

Pendidikan di Taiwan mendorong mahasiswa untuk berpartisipasi aktif dalam pembelajaran. Di kelas, mahasiswa diajar oleh dosen profesional yang memahami kebutuhan mahasiswa. Selain itu, kampus memfasilitasi mahasiswa untuk bekerja sama dengan institusi lain untuk melakukan praktik lapangan. Pengalaman belajar tersebut dapat meningkatkan kemampuan dan keterampilan mahasiswa dalam pencapaian tujuan belajar. Pembelajaran berbasis praktik adalah strategi yang efektif dan efisien untuk memperoleh keterampilan pemecahan masalah baru (Van, Hoogerheide, Verkoeijen \& Van, 2019).

Pembelajaran di Taiwan lebih banyak melibatkan mahasiswa bekerja di laboratorium daripada belajar di kelas. Hal ini dapat meningkatkan keterampilan mahasiswa di Taiwan. Di sisi lain, terdapat hambatan di mana mahasiswa yang belajar di Taiwan tidak dapat mengikuti kelas yang mereka inginkan sehingga mahasiswa harus menghadiri kelas lain yang terkait dengan mata kuliah mereka. Namun, hambatan yang dihadapi mahasiswa Indonesia adalah keterbatasan dalam menjalin komunikasi dengan beberapa mahasiswa lokal yang kurang dapat berbahasa Inggris dengan baik. Seperti kutipan mahasiswa di bawah ini:

Berbahasa Inggris yang baik namun sesederhana mungkin karena bahasa sehari-hari mereka di sini bukan bahasa Inggris namun Mandarin. (Bi. Desember 2018) 
Selain itu, masalah bahasa memengaruhi partisipan dalam hal berperan aktif di kelas, berinteraksi dengan dosen dan menyelesaikan tugas akademik yang mengakibatkan prestasi akademik yang kurang memuaskan.

Pada semester pertama, hasil akademik saya tidak sebagus semester berikutnya karena kesulitan bahasa sehingga saya tidak mengerti pelajarannya. (Rb. Januari 2019)

Mahasiswa dari Indonesia mengalami kesulitan dalam memahami penjelasan yang diberikan dosen lokal ketika belajar di kelas karena tidak semua dosen dapat berbicara bahasa Inggris secara fasih.

Dosen dapat berbahasa Inggris namun pengucapannya kurang jelas sehingga kami bingung mengartikannya. (An. Desember 2018)

Perbedaan pemahaman yang diakibatkan oleh pelafalan bahasa dosen yang kurang jelas dapat memengaruhi pencapaian akademik mahasiswa. Shen, Kim dan Benner (2019) menegaskan bahwa pemahaman bahasa yang kurang komprehensif serta penggunaan kata yang kurang sesuai dalam konteks penyampaian dapat menyebabkan masalah bagi mahasiswa dalam menginterpretasikan makna dan mencapai tujuan pembelajaran.

\section{Dimensi Sosial: "Perlu dukungan sosial dari pihak kampus"}

Kurangnya rasa percaya diri untuk berkomunikasi dengan masyarakat lokal, kekhawatiran untuk tidak diterima dan gaya hidup serta karakter yang berbeda merupakan efek lain dari gegar budaya yang disebabkan oleh masalah bahasa. Kemampuan bahasa yang terbatas akan menyebabkan masalah komunikasi yang menjadi hambatan sosial yang dirasakan mahasiswa (Shen, Kim \& Benner, 2019). Seorang partisipan menyatakannya sebagai berikut:

Saya merasa enggan berteman dengan orang asli Taiwan karena saya tidak bisa berbicara bahasa mandarin dengan lancar dan saya tidak memiliki pikiran yang sama dengan mereka. (Yn. Januari 2019)

Sangat susah untuk beribadah jika satu kamar dengan teman dari mahasiswa lokal karena mereka aktif di malam hari dan baru tidur di waktu subuh saat kami baru bangun tidur. (Ha. November 2018)

Dari perspektif sosial, mahasiswa baru merasa sulit untuk berkomunikasi dengan orang Taiwan ketika berdiskusi bersama. Selain masalah bahasa, partisipan juga mengalami kesulitan melaksanakan ibadah, terutama untuk mahasiswa muslim karena mereka tinggal satu kamar dengan mahasiswa lokal non-muslim. Misalnya, ketika mereka ingin salat Subuh, mahasiswa lokal sedang tidur. Kondisi ini mengakibatkan mahasiswa Indonesia merasa tidak nyaman. Masalah lain yang dialami oleh mahasiswa baru adalah tentang kebersihan kamar mandi. Hal ini tecermin dari penjelasan partisipan berikut. 
Meski setiap pagi seseorang telah membersihkan kamar mandi, kamar mandi masih kotor karena kurangnya kebersihan pada pengguna kamar mandi. Tisu bekas berserakan di lantai dan kadang-kadang kotoran di lantai. (Md. Desember 2018)

Kebersihan sangat memengaruhi kondisi mental dan psikologis mahasiswa baru karena kondisi yang berantakan dapat mengakibatkan ketidaknyamanan. Cao, Zhu dan Meng (2016) mengungkapkan bahwa kondisi di sekitar yang berantakan dapat membuat mahasiswa sulit berkonsentrasi terhadap tugas kuliah. Perbedaan kebiasaan memengaruhi proses adaptasi sosial dalam hubungan antarmahasiswa internasional. Mahasiswa membutuhkan dukungan sosial dari teman sebaya, organisasi dan dari pihak kampus untuk mengurangi dampak gegar budaya. Partisipan berkomentar mengenai upaya yang dilakukan oleh kampus, seperti diungkap dalam data wawancara berikut.

Saat awal kami mendapat welcome party dari kampus dan organisasi kemahasiswaan di sana kami mendapatkan informasi dan tips yang bermanfaat mengenai transportasi dan tempat makanan. (Bi. November 2018)

Dukungan sosial yang diberikan oleh pihak kampus membantu menyampaikan pesan bahwa mereka tidak sendirian di lingkungan dan budaya yang baru ini. Penerimaan pihak kampus terhadap mahasiswa Indonesia menunjukkan sikap empati yang baik dalam membantu mereka melakukan adaptasi sosial. Dukungan sosial dapat memengaruhi kesejahteraan sosial bagi mahasiswa baru di Taiwan. Lingkungan sosial yang memengaruhi motivasi belajar di Taiwan adalah interaksi dan komunikasi sosial. Dukungan sosial dan penerimaan lingkungan adalah salah satu bagian yang dapat meningkatkan kesejahteraan psikologis mahasiswa (Moeller \& Seehuus, 2019). Dukungan emosional, pertukaran informasi dan penghargaan berdasarkan pengalaman bersama keluarga dan teman-teman berpengaruh terhadap penilaian afektif dan kasih sayang dalam dukungan sosial (Poyrazli, Kavanaugh, Baker \& AlTimimi, 2004).

\section{Dimensi Budaya: "Masyarakat di sini jujur dan tertib"}

Budaya Taiwan sangat berbeda dengan budaya Indonesia. Orang Taiwan menerapkan budaya antri, misalnya saat naik bus atau membeli sesuatu walaupun antriannya panjang. Berikut ini data wawancara yang menunjukkan perbedaan budaya tersebut.

Selain itu, budaya Taiwan yang berbeda dari Indonesia adalah tentang penumpang, ada aturan yang baik di Taiwan, ketika ada penumpang muda, ada penumpang tua yang naik bus, pemuda itu berdiri dan mengajaknya untuk duduk. Di jalan Taiwan, pengguna menggunakan jalan kanan, berbeda dengan Indonesia, pengguna jalan kiri. (Mg. November 2018) 
Seperti yang disampaikan oleh partisipan, penerapan aturan di Taiwan cukup baik. Penerapan norma kesopanan dan saling menghargai merupakan identitas orang asli Taiwan yang diajarkan sejak kecil dan telah menjadi kebiasaan. Bankston dan Hidalgo (2006) menunjukkan bahwa sifat menghormati kepada yang lebih tua dipengaruhi oleh pengalaman pribadi, kebudayaan, institusi pendidikan dan agama.

Masalah perbedaan budaya yang dihadapi oleh mahasiswa Indonesia juga berkaitan dengan kesulitan untuk mendapatkan makanan halal yang sesuai dengan selera dan menemukan tempat beribadah, seperti tanggapan salah satu mahasiswa berikut:

Sulit untuk mendapatkan makanan yang halal karena berkaitan dengan agama yang saya anut. Ada yang halal namun tidak sesuai dengan selera, serta sangat sulit untuk mencari tempat beribadah. (Fr. November 2018)

Kesulitan yang dihadapi oleh mahasiswa untuk menjalankan aturan agama dalam hal ini, misalnya memilih makanan yang halal serta menjalankan ibadah menjadi tantangan tersendiri. Wahidati dan Sarinastiti (2018) menyarankan bagi muslim yang ingin berkunjung ke Asia Timur untuk mempertimbangkan ketersediaan rumah makan halal dan keterbatasan fasilitas ibadah yang tersedia. Nilai dan kepercayaan yang dibagikan secara budaya memainkan peran penting dalam keyakinan dan perilaku konsumen tentang produk makanan baru (Lo Monaco \& Bonetto, 2019).

Mahasiswa baru Indonesia juga berpendapat bahwa masyarakat Taiwan pada umumnya sangat jujur. Hal ini seperti yang disampaikan oleh mahasiswa tersebut.

Masyarakat di sini jujur dan tertib sekali jika ada uang atau kartu mahasiswa yang terjatuh, maka barang tersebut akan dibiarkan pada tempatnya atau diserahkan kepada pihak keamanan. (Df. Desember 2018)

Dalam penelitian sosial, nilai-nilai kejujuran menjadi poin penting dalam menambah pengalaman mahasiswa Indonesia di Taiwan. Budaya jujur melahirkan konsepsi yang mendasar tentang diri, hubungan yang baik dalam berinteraksi sosial dan merupakan perwujudan kesehatan mental. Ryff dan Singer (1996) menyampaikan bahwa dimensi kesejahteraan dalam budaya timur lebih berorientasi pada hubungan ketergantungan orang lain, seperti hubungan positif dengan orang lain.

\section{SIMPULAN DAN IMPLIKASI}

Penelitian ini bertujuan untuk membahas kesejahteraan psikologis mahasiswa baru Indonesia di Taiwan. Temuan penelitian mengungkapkan bahwa persiapan sebelum keberangkatan ke negara tujuan belajar harus dilakukan dengan baik untuk mengurangi kemungkinan masalah kesejahteraan psikologis yang dihadapi oleh mahasiswa. Studi ini memberikan bukti empiris tentang dampak 
gegar budaya terhadap kesejahteraan psikologis mahasiswa baru Indonesia di Taiwan. Aspek yang menjadi kendala utama adalah bahasa yang disebabkan oleh keterbatasan mahasiswa Indonesia dalam menggunakan bahasa lokal. Masalah ini memengaruhi kelancaran mereka untuk berinteraksi sosial dengan masyarakat lokal Taiwan. Selain kendala bahasa, perbedaan kebiasaan jam tidur antara mahasiswa Indonesia dengan mahasiswa lokal Taiwan menimbulkan ketidaknyamanan bagi mahasiswa Indonesia. Oleh karena itu, mahasiswa baru perlu membangun keterampilan beradaptasi saat sedang berkuliah di Taiwan.

Penelitian ini berimplikasi pada mahasiswa yang berencana melanjutkan studi di Taiwan terlebih di masa pandemi dan pascapandemi COVID-19. Banyak negara, termasuk pemerintah Taiwan, membuat kebijakan yang lebih ketat dalam hal penerimaan mahasiswa baru internasional selama wabah korona masih belum bisa dikendalikan. Hal tersebut dapat berdampak terhadap rencana studi calon mahasiswa baru internasional asal Indonesia di Taiwan dikarenakan kekhawatiran mengenai pembatasan perjalanan serta peningkatan biaya hidup di luar negeri. Kebijakan karantina wilayah berpotensi membuat mahasiswa Indonesia dan internasional lainnya mengalami tekanan sosial dan psikologis (Ornell, Schuch, Sordi \& Kessler, 2020; Wenham, Smith \& Morgan, 2020). Rekomendasi penelitian ini ditujukan kepada calon mahasiswa yang akan belajar di Taiwan untuk melakukan persiapan yang matang mencakup aspek bahasa, fisik, psikologis, geososial dan finansial. Di sisi lain, pihak universitas wajib memberikan dukungan untuk mempersiapkan strategi dalam penerimaan mahasiswa baru dan sistem pembelajaran daring di masa pandemi dan pascapandemi COVID-19.

\section{Pernyataan Penulis [Disclosure Statement]}

Penulis menyatakan bahwa tidak ada konflik kepentingan dalam hal riset, kepengarangan, dan publikasi artikel ini. [The authors declared no potential conflicts of interest with respect to the research, authorship, and/or publication of this article].

\section{Pernyataan Kontribusi Penulis [Authors' Contribution Statements]}

Ferry Fadzlul Rahman: Menulis artikel awal (pendukung), mengonsep ide (pendukung), mengolah data (utama), mengedit (utama) dan mengevaluasi (utama) [writing-original draft (supporting), conceptualization (supporting), analyze data (lead), editing (lead), evaluation (lead)]; Hamka: Mengumpulkan data (utama), mengonsep ide (pendukung), merancang metode penelitian (pendukung), menulis dan mengedit artikel awal (utama), mengolah data (pendukung) [data collecting (lead), conceptualization (supporting), methodology (supporting), writing and editing original draft (lead), analyze data (supporting)]; Kuan-han Lin: Mengonsep ide (utama), merancang metode penelitian (pendukung) [conceptualization (lead), methodology (supporting)].

\section{DAFTAR REFERENSI}

Akhtar, M., \& Kroener-Herwig, B. (2019). Coping styles and socio-demographic variables as predictors of psychological well-being among international students belonging to different cultures. Current Psychology, 38(3), 618626. DOI: $10.1007 / \mathrm{s} 12144-017-9635-3$ 
Bankston, C. L., \& Hidalgo, D. A. (2006). Respect in Southeast Asian American children and adolescents: Cultural and contextual influences. New Directions for Child and Adolescent Development,06(114), 25-38. DOI: 10.1002/cd.173

Batram, B. (2008). Supporting international students in higher education: Constructions, cultures and clashes. Teaching in Higher Education, 13(6), 657-668.

Brunsting, N. C., Zachry, C., \& Takeuchi, R. (2018). Predictors of undergraduate international student psychosocial adjustment to US universities: A systematic review from 2009-2018. International Journal of Intercultural Relations, 66, 22-33. DOI: 10.1016/j.ijintrel.2018.06.002

Carruthers, C. P., \& Hood, C. D. (2004). The power of the positive: Leisure and well-being. Therapeutic Recreation Journal, 38(2), 225-245.

Cao, C. Zhu, C., \& Meng, Q. (2016). An exploratory study of inter-relationships of acculturative stressors among Chinese students from six European unions (EU) countries. International Journal of Intercultural Relations, 55, 8-19. DOI: 10.1016/j.ijintrel.2016.08.003

Chen, Y. L., Liu, M. C., Tsai, T. W., \& Chen, Y. H. (2015). Religious practices in cross-cultural contexts: Indonesian male science students' adjustment in Taiwan. Journal of Counseling Psychology, 62(3), 464-475.

Gallagher, S. (2012). Phenomenology. London: Palgrave Macmillan.

Harvey, L. (2017). Language learning motivation as ideological becoming. System, 65, 69-77. DOI: 10.1016/j.system.2016.12.009

Huffman, J., Inoue, M., Asahara, K., Oguro, M., Okubo, N., Umeda, M., \& Shimoda, K. (2020). Learning experiences and identity development of Japanese nursing students through study abroad: A qualitatie analysis. Int $J$ Med Educ, 11, 54-61. DOI: 10.5116/ijme.5e47.cf1b

Leathwood, C., \& O'Connell, P. (2003). 'It's a struggle': The construction of the 'new student' in higher education. Journal of Education Policy, 18(6), 597615.

Lo Monaco, G., \& Bonetto, E. (2019). Social representations and culture in food studies. Food Research International, 115, 474-479. DOI: 10.1016/j.foodres.2018.10.029

Moeller, R. W., \& Seehuus, M. (2019). Loneliness as a mediator for college students' social skills and experiences of depression and anxiety. Journal of Adolescence, 73, 1-13. DOI: 10.1016/j.adolescence.2019.03.006

Niehaus, E., Bryan, A., Nelson, M. J., \& Briscoe, K. (2020). Addressing students' mental health needs in faculty-led study abroad courses. Journal of College Student Psychotherapy. Terbit pertama online (hlm. 1-23). DOI: 10.1080/87568225.2020.1760160

Ornell, F., Schuch, J. B., Sordi, A. O., \& Kessler, F. H. P. (2020). "Pandemic fear" and COVID-19: Mental health burden and strategies. Brazilian Journal of Psychiatry, 42(3), 232-235. DOI: 10.1590/1516-4446-2020-0008

Paige, R. M., \& Cohen, A. D. (2012). Maximizing study abroad: A students' guide to strategies for language and culture learning and use: ERIC. The Slavic and East European Journal, 47(2), 239-241. DOI: 10.2307/3219974

Poyrazli, S., Kavanaugh, P. R., Baker, A., \& Al-Timimi, N. (2004). Social support and demographic correlates of acculturative stress in international students. Journal of College Counseling, 7(1), 73-82. 
Reiter, S., Stewart, G., \& Bruce, C. S. (2011). A strategy for delayed research method selection: Deciding between grounded theory and phenomenology. Electronic Journal of Business Research Methods, 9(1), 35-46.

Rujipak, V., \& Limprasert, S. (2016). International students' adjustment in Thailand. ABAC Journal, 36(1), 34-46.

Ryff, C. D. (1995). The structure of psychological well-being revisited. Journal of personality and social psychology,69(4), 719-727. DOI: 10.1037/00223514.69.4.719

Ryff, C. D., \& Singer, B. (1996). Psychological well-being: Meaning, measurement, and implications for psychotherapy research. Psychotherapy and Psychosomatics, 65(1), 14-23. DOI: 10.1159/000289026

Shen, Y., Kim, S. Y., \& Benner, A. D. (2019). Burdened or efficacious? Subgroups of Chinese American language brokers, predictors, and long-term outcomes. Journal of youth and adolescence,48(1), 154-169. DOI: 10.1007/s10964-018-0916-4

Tanis, H. (2013). Pentingnya pendidikan character building dalam membentuk kepribadian mahasiswa [The importance of character building education in shaping student personality]. Humaniora, 4(2), 1212-1219.

Unanue, W., Vignoles, V. L., Dittmar, H., \& Vansteenkiste, M. (2016). Life goals predict environmental behavior: Cross-cultural and longitudinal evidence. Journal of Environmental Psychology, 46, 10-22. DOI: 10.1016/j.jenvp.2016.02.001

Van Harsel, M., Hoogerheide, V., Verkoeijen, P., \& Van Gog, T. (2019). Effects of different sequences of examples and problems on motivation and learning. Contemporary Educational Psychology, 58, 260-275. DOI: 10.1016/j.cedpsych.2019.03.005

Vande Berg, M. (2007). Intervening in the Learning of U.S. Students Abroad, 11(34), 392-399. DOI: 10.1177/1028315307303924

Wahidati, L., \& Sarinastiti, E. N. (2018). Perkembangan wisata halal di Jepang. [Development of halal tourism in Japan]. Jurnal Gama Societa, 1(1), 9-19.

Wenham, C., Smith, J., \& Morgan, R. (2020). COVID-19: The gendered impacts of the outbreak. The Lancet, 395(10227), 846-848. DOI: 10.1016/S01406736(20)30526-2

Widodo, H. P. (2014). Methodological considerations in interview data transcription. International Journal of Innovation in English Language Teaching and Research, 3(1), 101-107.

Will, N. L. (2016). From isolation to inclusion: Learning of the experiences of Chinese international students in US. Journal of International Students, 2016, 6(4), 1069-1075.

Yamada, Y., Klugar, M., Ivanova, K., \& Oborna, I. (2014). Psychological distress and academic self-perception among international medical students: The role of peer social support. BMC Medical Education, 14(1), 256-261.

Yilmaz, N. D., Sahin, H., \& Nazli, A. (2020). International medical students' adaptation to university life in Turkey. International Journal of Medical Education, 11, 62-72. DOI: 10.5116/ijme.5e47.d7de

Zhang, J., \& Goodson, P. (2011). Predictors of international students' psychosocial adjustment to life in the United States: A systematic review. International Journal of Intercultural Relations, 35(2), 139-162. DOI: 10.1016/j.ijintrel.2010.11.011 


\section{BIOGRAFI SINGKAT PENULIS [NOTES ON CONTRIBUTORS]}

Ferry Fadzlul Rahman (penulis korespondensi) adalah seorang Mahasiswa Pascasarjana Administrasi Kesehatan di Asia University, Taiwan dan juga berprofesi sebagai dosen Kesehatan Masyarakat di Universitas Muhammadiyah Kalimantan Timur. Minat penelitian utama penulis adalah hukum kesehatan, pendidikan kesehatan, serta penuaan dan kesehatan.Email: ffr607@umkt.ac.id

Ferry Fadzlul Rahman (corresponding author) is a postgraduate student in the Department of Healthcare Administration at Asia University in Taiwan. He is also a Lecturer in the Department of Public Health at Universitas Muhammadiyah Kalimantan Timur. His main research interests lie in health law, health education, and aging and health. Email: ffr607@umkt.ac.id

Hamka adalah Mahasiswa Pascasarjana di Departemen Psikologi di Asia University, Taiwan dan juga berprofesi sebagai dosen Psikologi Universitas Muhammadiyah Kalimantan Timur. Minat penelitian penulis adalah psikologi pendidikan.Email: ham807@umkt.ac.id

Hamka is a Postgraduate Student in the Department of Psychology of Asia University, Taiwan. He lectures on psychology at Universitas Muhammadiyah Kalimantan Timur. His research focuses on educational psychology. Email:ham807@umkt.ac.id

Kuan-Han Lin adalah seorang profesor di Departemen Administrasi Kesehatan di Asia University, Taiwan. Dia memperoleh gelar PhD dari Institute of Occupational Medicine dan Industrial Hygiene di National Taiwan University pada tahun 2013. Dia menerbitkan berbagai artikel tentang stres pasca-trauma di antara pekerja yang terluka dan do-not-resuscitate pada pasien perawatan kritis di jurnal akademik internasional utama, termasuk BMC Medical Ethics, Neurourology and Urodynamics, Scientific Reports dan Occupational Medicine. Minat penelitian utama penulis adalah epidemiologi di pekerjaan dan lingkungan, kesehatan kerja, stres kerja dan kelelahan, dan bioetika. Email: okonkwolin@asia.edu.tw

Kuan-Han Lin is an Assistant Professor in the Department of Healthcare Administration at Asia University in Taiwan. She obtained her PhD degree from the Institute of Occupational Medicine and Industrial Hygiene at National Taiwan University in 2013. She has published various articles on the post-traumatic stress orders among injured workers and do-not-resuscitate in critical care patients in major international academic journals, including BMC Medical Ethics, Neurourology and Urodynamics, Scientific Reports, and Occupational Medicine. Her main research interests lie in occupational and environmental epidemiology, occupational health, occupational stress and burnout, and bioethics. Email: okonkwolin@asia.edu.tw 